\title{
Natural Murine Autoantibodies and Conventional Antibodies Exhibit Similar Degrees of Antigenic Cross-reactivity
}

\author{
Dennis M. Klinman, “‡ Steven Banks, ${ }^{5}$ Antoinette Hartman," and Alfred D. Steinberg ${ }^{\star}$ \\ *Cellular Immunology Section, Arthritis and Rheumatism Branch, National Institute of Arthritis and Musculoskeletal and Skin \\ Diseases; ${ }^{\ddagger}$ Infectious Disease Branch, NINCDS; ${ }^{\S}$ National Institutes of Allergy and Infectious Diseases, "Laboratory of Oral Medicine, \\ National Institutes of Dental Research, National Institutes of Health, Bethesda, Maryland 20892
}

\begin{abstract}
Splenic B cells from normal and autoimmune mice were transferred to MHC-compatible xid recipients. Monoclonal antibodies were secreted by the transferred $B$ cells in splenic fragment cultures. These antibodies were evaluated for reactivity and cross-reactivity against a panel of six autoantigens and two conventional antigens using an ELISA assay. The autoantibodies and conventional antibodies produced in splenic fragment cultures by normal DBA/ 2 and autoimmune NZB B cells expressed similar degrees of antigenic cross-reactivity.

Previous studies have demonstrated that ELISA assays of splenic fragment culture supernatants detect antibodies with affinities of $5 \times 10^{6} \mathrm{M}^{-1}$ or greater. We therefore also analyzed the cross-reactivity.of monoclonal antibodies derived from hybridomas. This permitted an assessment of antibodies with lower binding affinities. Cross-reactivity was detected more frequently among these hybridomas. Consistent with our earlier observations, hybridoma antibodies specific for conventional antigens exhibited cross-reactivity with a frequency similar to that of antibodies specific for autoantigens.
\end{abstract}

\section{Introduction}

Systemic lupus erythematosus (SLE) in humans and animals is characterized by the presence of elevated levels of serum antibodies reactive with a variety of self-antigens, including cell membrane molecules, cytoplasmic proteins, and nuclear determinants $(1,2)$. Two divergent models have been proposed to explain the diversity of autoantibodies produced in SLE. The first holds that many different $B$ cells are activated and that each $B$ cell produces antibodies reactive with a single self-antigen. The other model holds that far fewer $\mathbf{B}$ cell clones are activated, but that these cells produce antibodies that are highly cross-reactive.

In the first model, autoantibodies and conventional antibodies are viewed as having similar levels of cross-reactivity and as arising from a common pool of B cells. This differs from the second model, where unique subsets of B cells (such as those expressing the Lyl surface marker or utilizing unmutated germline Ig genes) are believed responsible for most autoantibody production (3-5). Differentiating between these alternatives has major implications concerning the etiopathogenesis and treatment of SLE. Evidence supporting the second model includes $(a)$ isolation of B cell hybridomas capable of

Address reprint requests to Dr. Klinman, Bldg. 36, Rm. 5D 06, National Institutes of Health, Bethesda, MD 20892.

Received for publication 19 March 1987 and in revised form 9 February 1988

The Journal of Clinical Investigation, Inc.

Volume 82, August 1988, 652-657 secreting highly cross-reactive autoantibodies (6-9), (b) detection of cross-reactive autoantibodies in the serum of autoimmune animals (10), (c) preferential utilization of $3^{\prime} \mathrm{IgVh}$ region genes by autoantibody-producing hybridomas $(5)$ and $(d)$ identification of $\mathrm{Lyl}^{+} \mathrm{B}$ cells and determining that they contribute disproportionately to the production of autoantibodies $(3,4)$. In contrast, it has also been demonstrated that autoantibodies are similar to conventional antibodies, in that both $(a)$ undergo isotype and affinity maturation (11-13), (b) arise from a variety of $\mathrm{IgVh}$ region genes (14), (c) are acted upon by somatic mutation (15) and (d) are expressed at equivalent frequencies in the repertoires of normal and autoimmune mice (16).

We recently demonstrated that natural autoantibodies could be analyzed at the clonal level using a splenic fragment transfer system $(17,18)$. B cells from normal DBA/2 and autoimmune NZB mice were transferred to MHC-compatible xid recipients where they engrafted and proliferated $(17,18)$. Native B cells of the xid recipient did not produce detectable levels of autoantibody due to the effect of the X-linked immunodeficiency gene on endogenous $B$ cell function. A sensitive ELISA assay facilitated the detection of antibodies produced by donor B cells in fragment cultures. Previous work indicated that antibodies with an affinity of $5 \times 10^{6} \mathrm{M}^{-1}$ or greater could be detected in such a system (19). The antibodies present in these culture supernatants were monoclonal, as demonstrated by their expression of a single Ig heavy and light chain isotype (17-23).

In this report, limiting numbers of donor B cells were transferred to xid recipients and the degree of cross-reactivity of the monoclonal antibodies produced by such cells examined. Over 1200 splenic fragment supernatants were analyzed for reactivity against a large panel of autoantigens and conventional antigens. Findings from these studies were correlated to observations made using hybridoma antibody panels. Our results indicate that antibodies produced by $B$ cells from autoimmune NZB mice were not more cross-reactive than those from normal DBA/2 mice, and that autoantibodies were not significantly more cross-reactive than antibodies of conventional antigenic specificity.

\section{Methods}

Animals. DBA/2 mice were obtained from The Jackson Laboratory, Bar Harbor, ME, while NZB and $(\mathrm{DBA} / 2 \cdot x i d / x i d \times \mathrm{NZB} \cdot x i d) \mathrm{F}_{1}$ (hereafter $F_{1} \cdot x i d$ ) mice were bred and raised in our animal colony. Females from 4 to 6 mo of age were used in all experiments. Sera from donors and recipients were tested for total Ig and autoantibody levels before use. Total antibody levels in $F_{1} \cdot x i d$ and DBA/2 mice were at least 15 times lower than those in NZB mice.

Splenic fragment culture system. The methodology for in vitro B cell cloning has been described previously (17-22). Briefly, a single cell suspension made from the spleens of two to four donor mice was treated twice with anti-Thy 1.2 plus complement (resulting in $<2 \% \mathrm{~T}$ 
Table I. Cross-reactivity of Hybridoma Autoantibodies

\begin{tabular}{|c|c|c|c|c|c|c|c|c|}
\hline Antibody & C.R. & Myo & Act & BrMRBC & $\mathrm{T}$ cell & Trans & TNP-KLH & Ova \\
\hline $2 G 8$ & Lo & 0 & 0 & 0 & + & 0 & 0 & 0 \\
\hline $4 B 12$ & Lo & 0 & 0 & 0 & + & 0 & 0 & 0 \\
\hline $6 \mathrm{Cl}$ & Lo & + & 0 & 0 & 0 & 0 & 0 & 0 \\
\hline 10D3 & Lo & 0 & + & + & 0 & 0 & 0 & 0 \\
\hline $8 \mathrm{Fl}$ & $\mathrm{Hi}$ & 0 & + & 0 & + & 0 & + & 0 \\
\hline $6 \mathrm{C} 4$ & $\mathrm{Hi}$ & + & + & + & + & + & + & + \\
\hline $6 \mathrm{E} 3$ & $\mathbf{H i}$ & + & + & + & + & + & + & 0 \\
\hline $9 \mathrm{G} 1$ & $\mathrm{Hi}$ & + & + & + & + & + & + & + \\
\hline
\end{tabular}

C.R. These hybridoma cell lines were originally detected by screening on a minimum of 6 autoantigens using an antigen-coated bead assay (Hartman, A. B., C. P. Mallett, J. Srinivasappa, B. S. Prabhakar, A. L. Notkins, and S. J. Smith-Gill. Manuscript submitted for publication.) Antibody-containing supernatants reacted with either 0-2 (Lo) or 3-6 (Hi) antigens from this panel. Supernatants from the same hybridomas were then tested for reactivity on our antigen panel by ELISA assay. Positive results are shown by a (+). Two additional autoantibody panels (gifts of Dr. C. Bona and P. Rousseau) were also examined with similarly concordant results (data not shown).

cell contamination as assessed by flow cytometry). The B cells were injected intravenously into unimmunized, unirradiated $\mathrm{F}_{1} \cdot$ xid recipients. Spleens from recipient mice were removed $20 \mathrm{~h}$ later and diced into 48 equal-sized fragments. Each fragment was sterilely cultured for $1 \mathrm{wk}$ in a microtiter well in medium consisting of RPMI 1640 supplemented with $10 \%$ fetal calf serum, $2 \mathrm{mM}$ L-glutamine, $5 \times 10^{-5} \mathrm{M}$ 2-mercaptoethanol, $10 \mathrm{mM}$ Hepes, $0.11 \mathrm{mg} / \mathrm{ml}$ sodium pyruvate, and penicillin $(100 \mathrm{U} / \mathrm{ml})$ and streptomycin $(100 \mu \mathrm{g} / \mathrm{ml})$. Fresh media was added after $4 \mathrm{~d}$.

Detection of antibodies by ELISA assay. $50 \mu \mathrm{l}$ of supernatant collected from splenic fragments cultured for $1 \mathrm{wk}$ or from hybridoma supernatants containing $10 \mu \mathrm{g} / \mathrm{ml}$ of monoclonal antibody were analyzed for antibodies reactive with a panel of six autoantigens (singlestranded DNA, T cell surface antigens, bromelain-treated mouse red blood cells (BrMRBC),' myosin, actin, and transferrin) and two conventional antigens (TNP-KLH and ovalbumin) as described (16-18, 24). For the anti-DNA assay, Immulon I microtiter plates were coated with $10 \mu \mathrm{g} / \mathrm{ml}$ methylated bovine gamma-globulin to which was adsorbed heat-denatured single-stranded DNA $(10 \mu \mathrm{g} / \mathrm{ml})$. The specific recognition of DNA by antibodies in culture supernatants was detected using phosphatase-labeled goat antibody to total mouse Ig (Kirkegaard-Perry, Bethesda, MD [17]). The anti-T cell and anti-BrMRBC assays were similar, except that glutaraldehyde-fixed cells were used to coat the Immulon plates. Assays for protein antigens involved the direct adsorption of antigens (2-10 $\mu \mathrm{g} / \mathrm{ml}$ in carbonate buffer, $\mathrm{pH} 9.5)$ onto the microtiter plates, which were then used to detect the presence of antigen-reactive antibodies, as above (5).

In all assays, a fragment supernatant was scored as positive if the concentration of specific antibodies was more than three standard deviations above the mean of similarly cultured splenic fragments from unmanipulated $F_{1} \cdot x i d$ mice. When xid or $B$ cell depleted spleen cells were transferred to $F_{1} \cdot x i d$ recipients, $<1 \%$ of splenic fragments scored positive for autoantibody production under identical conditions.

Hybridoma antibodies. Four panels of hybridoma antibodies were utilized in this work. The methodology for their production and cloning has been described elsewhere in detail $(5,25)$.

Statistical analysis. The observed distribution of antibodies was compared with the expected distribution (which assumed independence) using chi-square analysis. Pairs of relative frequencies were compared using the Fisher exact test (26), while multiple comparisons of means were carried out using the Scheffe test (27).

1. Abbreviations used in this paper: $\mathrm{BrMRBC}$, bromelain-treated mouse red blood cells; C.R., cross reactivity; Ags, antigens; myo, myosin; act, actin; trans, transferrin, ova, ovalbumin.

\section{Results}

Low-affinity cross-reactions involving hybridoma antibodies. To establish that our assay system could detect and differentiate between $\mathrm{B}$ cell clones producing mono-reactive and cross-reactive antibodies, a panel of monoclonal autoantibodies of known specificity was examined. Our ELISA assay detected the cross-reactive members of this panel as readily as did the original screening technique (Table I). Members of the antibody panel (selected at random) were grown in microtiter plates and analyzed under conditions identical to those used in the splenic fragment assay system. The reactivity and cross-reactivity of these monoclonal antibodies with antigens used in this study was determined with $97 \%$ accuracy. In addition to the hybridomas shown in Table I, results from 27 more are included in Table VI.

We further verified the specificity of our ELISA assays using a panel of monoclonal antibodies kindly provided by Dr. C. Bona $(5,25)$. Following the method of Monestier et al., cross-reactivity was studied using antibody concentrations of $3-10 \mu \mathrm{g} / \mathrm{ml}$. Such high concentrations of antibody permitted the detection of antigen-antibody interactions with affinities as low as $2 \times 10^{4} \mathrm{M}^{-1}(25)$. Cross-reactivity was detected in half of the autoantibodies studied by this method (see Table I).

A panel of hybridoma antibodies specific for the non-autoantigen phosphorylcholine (kind gift of Dr. P. Gearhart [28]) was then analyzed. Under conditions identical to those used above, $44 \%$ of these antibodies reacted with two or more members of the antigen panel (Table II). Thus, cross-reactivity was common among hybridoma antibodies specific for conventional antigens as well as autoantigens when tested at high antibody concentrations.

Antibodies produced by $B$ cells from autoimmune $N Z B$ and normal $D B A / 2$ mice show similar degrees of cross-reactivity. Antibodies produced by hybridomas may not reflect the normal B cell repertoire (29). Moreover, hybridoma panels generated under one set of conditions in one laboratory may differ from those generated under different conditions in another laboratory. We therefore used the splenic fragment transfer system to study the specificity and cross-reactivity of monoclonal antibodies derived from different types of donor B cells raised under identical conditions. Limiting numbers of $B$ cells 
Table II. Cross-reactivity of Anti-phosphorylcholine Antibodies

\begin{tabular}{lcccccccc}
\hline Antibody & Anti-PC & Myo & Act & BrMRBC & T cell & Trans & TNP-KLH & Ova \\
\hline HPCG 23 & + & 0 & 0 & 0 & 0 & 0 & 0 & 0 \\
HPCG 28 & + & 0 & 0 & 0 & 0 & 0 & 0 \\
M 5 11 & + & 0 & 0 & 0 & 0 & 0 & 0 & 0 \\
HPCG 20 & + & 0 & 0 & 0 & 0 & 0 & 0 \\
HPCG 15 & + & 0 & 0 & 0 & 0 & 0 & 0 \\
HPCG 24 & + & 0 & 0 & 0 & 0 & 0 & 0 \\
HPCG 32 & + & 0 & 0 & 0 & 0 & 0 & 0 \\
M 167 & + & 0 & 0 & 0 & + & 0 & 0 \\
HPCM 3 & + & 0 & 0 & + & 0 & 0 & 0 \\
HPCG 21 & + & 0 & 0 & + & + & 0 & 0 & 0 \\
HPCG 22 & + & 0 & 0 & + & + & 0 & 0 \\
HPCM 25 & + & 0 & 0 & + & + & 0 & 0 \\
MCPC 603 & + & + & 0 & + & + & 0 & 0 \\
TECP 15 & + & + & + & + & + & 0 & 0 \\
\hline
\end{tabular}

C.R. Antiphosphorylcholine secreting hybridoma cell lines (25) were analyzed for cross-reactivity with our panel of six autoantigens and two conventional antigens. Purified monoclonal antibodies at $3-10 \mu \mathrm{g} / \mathrm{ml}$ were used in this analysis.

from NZB and DBA/2 donors were transferred to MHC-compatible $\mathrm{F}_{1} \cdot x i d$ recipients. To compensate for the greater number of activated $B$ cells in NZB mice (18), sevenfold fewer NZB than DBA/2 B cells were transferred. The spleens of the recipient animals were removed one day later and cultured as fragments in vitro. Under these conditions, a majority of splenic fragments contained either zero or one autoantibody-secreting donor B cell. Autoantibody was absent from supernatants of splenic fragments devoid of donor B cells, since host (xid) lymphocytes secreted no detectable autoantibody (Table III).

Culture supernatants of fragments that contained donor cells were analyzed for the presence of antibodies specific for the autoantigens DNA, BrMRBC or T cell surface determinants. In some cases, supernatants contained antibodies reactive with more than one antigen (Fig. 1). These represented either cross-reactive antibodies or the seeding of two donor B cells into a single splenic fragment. The frequency of monoreactive and cross-reactive supernatants was compared in recipients of NZB and DBA/2 B cells. There was as much crossreactivity in the fragment supernatants derived from $\mathrm{DBA} / 2$ as from NZB donor B cells (Table III). To rule out the possibility that this result was influenced by use of an $F_{1}$ host, DBA/2 and NZB B cells were transferred to DBA/2 - xid recipients, Again, no significant difference in the frequency of cross-reactive supernatants was found when cells from normal and autoimmune donors were compared (Table III). The reactivity of NZB and DBA/2 lymphocytes was then examined against a larger panel of six autoantigens and two conventional antigens. Results of that study (Fig. 2 and Table IV) confirmed the similarity in antigenic reactivity of autoimmune NZB and normal DBA/2 B cells.

Natural autoantibodies and conventional antibodies show similar degrees of cross-reactivity. We analyzed whether autoantibody-containing supernatants reacted with additional autoantigens more frequently than supernatants containing antibodies of conventional antigenic specificity. $25.8 \%$ of supernatants reactive with the conventional antigens ovalbumin or TNP-KLH also reacted with at least one additional antigen. $22.5 \%$ of supernatants reactive only with autoantigens bound to an additional autoantigen. Statistical analysis of these find- ings, and of individual experiments in which $\mathrm{DBA} / 2$ and NZB B cells were transferred to NZB $\cdot x i d$ or DBA/2 $x$ xid recipients (Fig. 3), yielded similar results: there was no significant difference in the cross-reactivity of autoantibodies when compared to antibodies of conventional antigenic specificity.

To investigate whether antibodies which bound to particu-

Table III. Comparison of the Cross-reactivity of Donor NZB and $D B A / 2$ B Cells Passaged through Xid Recipients: Studies with Three Antigens

\begin{tabular}{|c|c|c|}
\hline & \multicolumn{2}{|c|}{$\begin{array}{l}\text { No. of splenic fragment } \\
\text { supernatants with indicated } \\
\text { reactivity }\end{array}$} \\
\hline & \multicolumn{2}{|c|}{$\begin{array}{c}F_{1} \cdot x i d \text { recipient } \\
(\text { Exp. 1) }\end{array}$} \\
\hline Ags Bound & $\underline{\mathrm{NZB}}$ & $\underline{\mathrm{DBA} / 2}$ \\
\hline None & 48 & 53 \\
\hline One & 39 & 34 \\
\hline Two & 7 & 9 \\
\hline \multirow[t]{2}{*}{ Three } & 2 & 0 \\
\hline & \multicolumn{2}{|c|}{$\begin{array}{l}\text { DBA } / 2 \cdot x i d \text { recipient } \\
(\text { Exp. 2) }\end{array}$} \\
\hline Ags Bound & $\underline{N Z B}$ & $\underline{\mathrm{DBA} / 2}$ \\
\hline None & 69 & 68 \\
\hline One & 22 & 20 \\
\hline Two & 5 & 6 \\
\hline Three & 0 & 2 \\
\hline
\end{tabular}

Experiments were performed as described in the legend to Fig. 1. Different donor cells were used in the two experiments. In $65 \%$ of multiply positive supernatants, antibodies reactive with each crossreactive antigen were present at the same concentration and expressed identical heavy and light chain isotypes. The remaining supernatants apparently reflected the random seeding of two different donor $B$ cells in the same splenic fragment. There was no significant difference in the cross-reactivity of NZB versus DBA/ 2 donor cells: chi square (three degrees of freedom) for $F_{1} \cdot x i d$ recipient was $=2.8$, $P>0.4$; for $\mathrm{DBA} / 2 \cdot x i d$ recipient was $2.27 P>0.5$. 


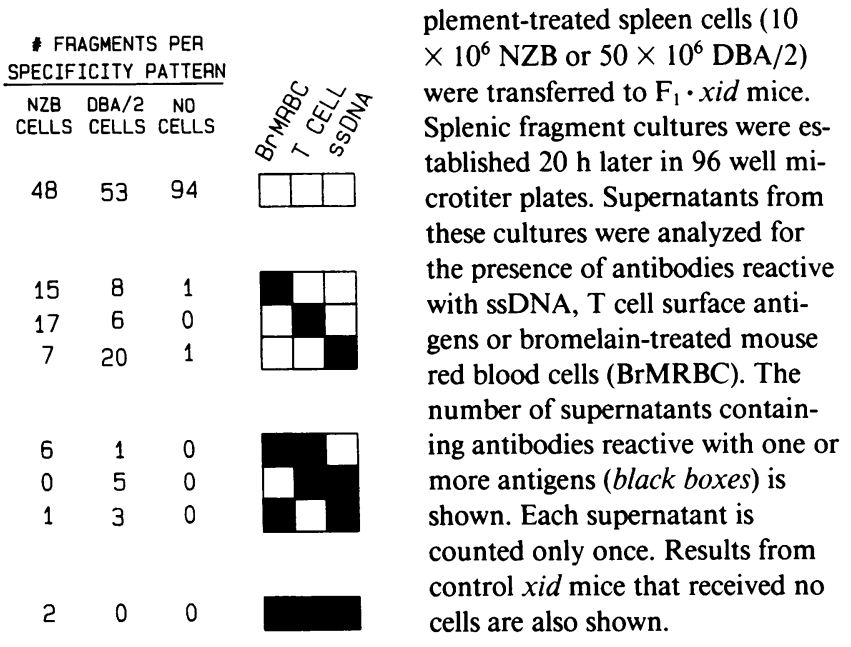

lar members of the antigen panel were unusually cross-reactive, larger numbers of NZB donor cells were transferred to $\mathrm{F}_{1} \cdot$ xid recipients. Under these transfer conditions, most splenic fragments contained antibody-secreting donor B cells. This provided enough antibody-containing culture superna-
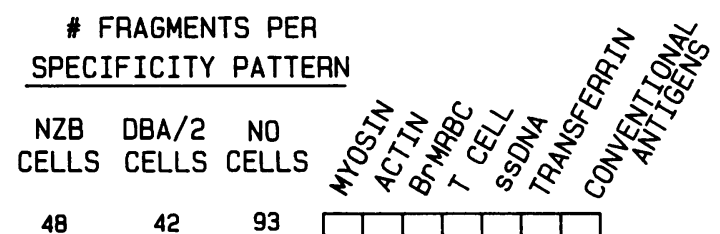

48

42

93
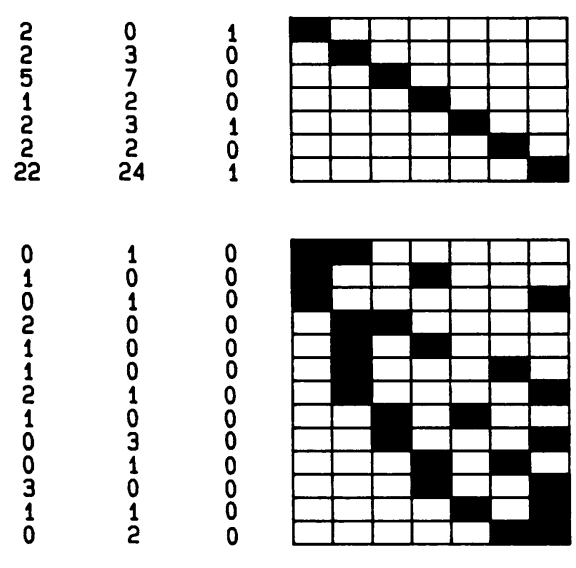

0

$\begin{array}{lll}1 & & 0 \\ 0 & & 0 \\ 1 & & 0 \\ 0 & & 0 \\ 0 & & 0 \\ 0 & & 0 \\ 1 & & 0 \\ 0 & & 0 \\ 3 & & 0 \\ 1 & & 0 \\ 0 & & 0 \\ 1 & & 0 \\ 2 & & 0 \\ & & \\ 1 & & 0 \\ 1 & & 0 \\ 1 & & \end{array}$

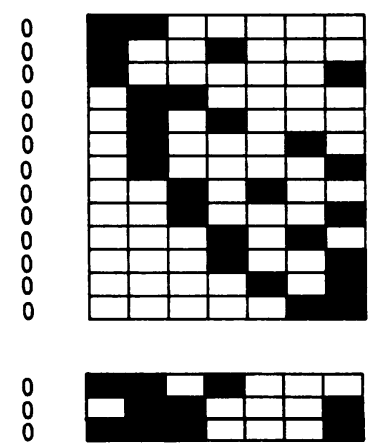

TOTAL: 96

96

96

Figure 2. Anti-Thy 1.2 plus complement-treated spleen cells $\left(5 \times 10^{6}\right.$ NZB and $35 \times 10^{6} \mathrm{DBA} / 2$ ) were transferred to $\mathrm{F}_{1} \cdot x i d$ mice. Splenic fragment culture supernatants were analyzed for antibodies reactive with a panel of conventional (TNP-KLH or ovalbumin) and autoantigens. The reactivity pattern of each supernatant (black box) is shown. Please note: due to differences in the expressed B cell repertoires of individual donor mice, the number of antibodies reactive with particular antigens varied between experiments. Such variability (up to fivefold for particular antigens) has been detected in a variety of other single-cell assays $(16,18,31)$.
Table IV. Comparison of the Cross-reactivity of $N Z B$ and DBA/2 B Cells-Study of Eight Antigens

\begin{tabular}{lcc} 
No. of Ags recognized & $\begin{array}{c}\text { No. of splenic fragment } \\
\text { supernatants with indicated } \\
\text { reactivity }\end{array}$ \\
\hline & NZB* & DBA/2* \\
None & 48 & 42 \\
One & 36 & 41 \\
Two & 12 & 10 \\
Three or more & 0 & 3
\end{tabular}

* Source of donor cells.

Experiments performed as described in the legend to Fig. 2. There was no significant difference in the reactivity of NZB versus DBA/2 donor cells: chi-square $3.67, P>0.25$ (three degrees of freedom).

tants to allow a meaningful comparison between B cells of each antigenic specificity. In all cases, the mean number of additional antigens bound by autoreactive supernatants was similar to the number of additional antigens bound by supernatants reactive with conventional antigens (Table V). Moreover, antibodies specific for particular autoantigens (such as DNA) were no more cross-reactive than antibodies that bound to other antigens.

\section{Discussion}

The cross-reactivity of naturally occurring autoantibodies was studied using a splenic fragment culture system and sensitive ELISA assays. Antibodies produced by normal DBA/2 and autoimmune NZB B cells exhibited similar degrees of antigenic cross-reactivity when raised under identical conditions. Furthermore, the autoantibodies secreted by NZB B cells were no more cross-reactive than the conventional antibodies produced by normal DBA/2 B cells. In studies of low-affinity cross-reactions involving hybridoma cell lines, we again found that autoantibodies and conventional antibodies exhibited similar degrees of cross-reactivity.

We have previously demonstrated that antibodies pro-

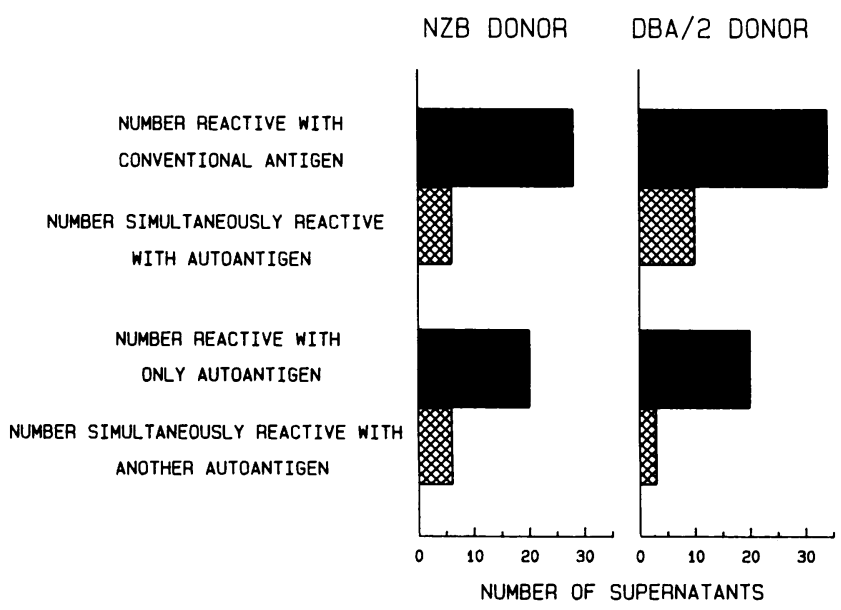

Figure 3. Supernatants containing "conventional" antibodies and those containing autoantibodies from the experiment describe in Fig. 2 were analyzed for their ability to bind to an additional antigen. Among these two populations, the proportion of supernatants reactive with more than one antigen was equivalent. 
Table V. Comparative Cross-reactivity of Antigen-specific Antibodies

\begin{tabular}{lcc}
\hline \multicolumn{1}{c}{ Antigen } & $\begin{array}{c}\text { Number of supernatants } \\
\text { with antibodies against } \\
\text { listed antigen }\end{array}$ & $\begin{array}{c}\text { Average number } \\
\text { of other antibodies } \\
\text { in well }\end{array}$ \\
\hline Conventional & 30 & $2.37 \pm 0.27$ \\
Myosin & 10 & $2.10 \pm 0.52$ \\
Actin & 49 & $2.38 \pm 0.18$ \\
BrMRBC & 46 & $2.17 \pm 0.19$ \\
T cell & 28 & $2.57 \pm 0.27$ \\
ssDNA & 47 & $2.21 \pm 0.19$ \\
\hline
\end{tabular}

$25 \times 10^{6}$ anti-Thy 1.2 plus complement-treated NZB spleen cells were transferred to $F_{1} \cdot x i d$ recipients. Splenic fragment cultures were established $20 \mathrm{~h}$ later in 96-well microtiter plates. The number of supernatants from these fragments which contained antibodies reactive with each of the test antigens is shown, as is the number of additional antigens recognized by those supernatants. Wells containing antibodies of conventional specificity showed the same degree of multiple binding as did wells containing autoantibodies (Scheffe multiple comparison test for means, $P>0.10$ ).

duced in $\mathrm{F}_{1} \cdot$ xid and $\mathrm{DBA} / 2 \cdot$ xid fragment cultures are of donor origin. It has been shown that: $(a)$ the number of autoantibody-secreting fragments correlates directly with the number of transferred donor lymphocytes $(17,18),(b)$ donor B cells are necessary and sufficient to transfer autoantibody production $(17,18)$ and $(c)$ antibodies produced in xid recipients reflect the Ig isotype and antigenic repertoire of the donor B cells (17).

When limiting numbers of donor B cells were transferred to xid recipients, a majority of splenic fragments contained either zero or one autoantibody-secreting lymphocyte. Under the experimental conditions used to generate the data in Tables III and IV, 10\% (5-13/96) of the splenic fragment supernatants reacted with two or more antigens. Approximately $35 \%$ of these multiply-reactive supernatants resulted from the seeding of two or more donor lymphocytes into a single splenic fragment. This conclusion was reached on the following evidence: $(a)$ in detailed studies of multiply-reactive culture supernatants, $35 \%$ of the antibodies binding to one antigen were of a different heavy or light chain isotype, or present at a different concentration, than antibodies from the same supernatant which bound to another antigen (Table III legend and (17)), and (b) this probability (35\%) of two donor B cells seeding a single fragment was consistent with the frequency predicted by Poisson analysis of the number of transferred B cells.

There was a marked difference in the amount of cross-reactivity among monoclonal antibodies raised in splenic fragment cultures when compared to monoclonal hybridoma antibodies as detected in our assays and those from other laboratories (Table VI). Such disparate results reflect differences in how these antibodies were generated and the affinity of the interactions involved. Antibodies produced in short-term splenic fragment cultures mirror the repertoire of B cells normally expressed by donor mice (16-22). Hybridomas arise from the fusion of donor B cells in a very specific stage of activation and differentiation. Thus, hybridomas may not reflect the normal immune repertoire (29).

It is also possible that the large amounts of Ig produced by hybridomas facilitate the detection of low-affinity antigen-antibody complexes. In this context, Monestier et al. recently analyzed the affinity of antibodies produced by autoreactive hybridomas (25). They found that the $K_{\mathrm{a}}$ for these interactions ranged from $8 \times 10^{3}$ to $7 \times 10^{5} \mathrm{M}^{-1}$. This raises two important questions: Do such low-affinity interactions have physiological relevance (antigen-induced serum antibody responses and hybridomas of conventional antigenic specificity have $K_{\mathrm{a}}$ 's on the order of $10^{6} \mathrm{M}^{-1}$ or greater, [30])? and, Do conventional antibodies show similar degrees of cross-reactivity when assayed under similarly nonstringent conditions?

We analyzed a panel of 14 antiphosphorylcholine (PC) binding antibodies. These antibodies bound to PC with an average $K_{\mathrm{a}}$ of $10^{7} \mathrm{M}^{-1}$ (Gearhart, P., personal communication). When tested at high concentration on our antigen panel, $44 \%$ cross-reacted with at least two other antigens (all bound PC). By comparison, Monestier found that $45 \%$ of monoclonal autoantibodies cross-reacted with conventional antigens (an observation we have since verified using many of the same antibodies). Thus, autoreactive and conventional antibodies produced by hybridomas can exhibit similar degrees of crossreactivity.

To detect low-affinity interactions $\left(10^{5} \mathrm{M}^{-1}\right.$ or less), antibodies concentrated to $10 \mu \mathrm{g} / \mathrm{ml}$ must be used. Splenic frag-

Table VI. Percent Monoclonal Antibody Cross-reactivity

\begin{tabular}{|c|c|c|c|c|c|c|c|}
\hline \multicolumn{3}{|c|}{ Splenic fragment assay } & \multicolumn{5}{|c|}{ Monoclonal antibody panels } \\
\hline No. of Ags & NZB & $\mathrm{DBA} / 2$ & A & B & $\mathrm{C}$ & D & $\mathbf{E}$ \\
\hline One & 78.9 & 83.3 & 13.6 & 17.4 & 37.5 & 22.2 & 12.5 \\
\hline Two & 19.5 & 14.5 & 18.2 & 30.4 & 0 & 0 & 20.8 \\
\hline Three & 1.6 & 4.7 & 9.1 & 47.8 & 50.0 & 0 & 54.2 \\
\hline Four & 0 & 0 & 31.8 & 4.4 & 0 & 44.4 & 12.5 \\
\hline$>$ Four & 0 & 0 & 27.3 & 0 & 12.5 & 33.3 & 0 \\
\hline
\end{tabular}

Calculations for NZB and DBA/2 mice include results from eight experiments in which no greater than $5 \times 10^{6} \mathrm{NZB}$ or $35 \times 10^{6} \mathrm{DBA} / 2 \mathrm{~B}$ cells were transferred to xid recipients. Note that only antibody-containing supernatants were included in this analysis. $(A)$ ELISA analysis of the monoclonal antibody panel shown in Table I and an additional 27 for which the data are not shown in Table I (Hartman et al., manuscript submitted). (B) A panel of 23 monoclonal antibodies, generated from 6-d-old LPS-stimulated BALB/c spleen cells, gave this distribution when tested for reactivity against a series of five autoantigens (6). (C) Eight monoclonal antibodies, generated from adult BALB/c and SJL/J mice, gave this distribution when tested for reactivity against six tissue sections. Note: tissue sections express multiple autoantigens, and different tissues may share the same autoantigens (8). (D) Nine monoclonal autoantibodies generated from patients with autoimmune diseases gave this distribution when assayed as in $C$ above (8). (E) 24 monoclonal anti-DNA antibodies, generated from six patients with SLE, gave this distribution when tested for cross-reactivity against three other autoantigens $(9)$. 
ments produce only 1-3 $\mu \mathrm{g}$ of monoclonal $\mathrm{Ig} /$ culture and therefore have been used to analyze physiologically relevant antibodies (i.e., those with affinities of $5 \times 10^{6} \mathrm{M}^{-1}$ or greater [19]). The utility of the fragment culture system for this purpose was demonstrated by its ability to detect the antigenic cross-reactivity of hemagglutinin proteins expressed by influenza viruses (22) and the idiotypic cross-reactivity of antiphosphorylcholine responses (21).

Our data support the intuitive expectation that antibody cross-reactivity increases as the affinity of the interactions examined decreases. More important, we found that autoantibodies and conventional antibodies express similar degrees of antigenic cross-reactivity when analyzed under similar conditions. Such a result is consistent with previous findings from our laboratory, which indicated that B cells which produced autoantibodies had functional properties similar to those of B cells that produced antibodies of conventional antigenic specificity. Taken together, these data suggest that a common pool of B cells may be responsible for the production of both autoantibodies and conventional antibodies.

\section{Acknowledgments}

We wish to thank Drs. Constantine Bona, Corey Mallett, and Patricia Gearhart for providing many of the hybridoma antibodies used in this study. Our thanks also to Drs. Jeffrey Siegel and Arthur Kreig for critical review of this manuscript and to Dr. David Alling for statistical analysis of the data. Dr. Klinman was supported by an Arthritis Foundation Fellowship.

\section{References}

1. Theofilopoulos, A. N., and F. J. Dixon. 1980. Immune complexes in human disease. A review. Am. J. Pathol. 100:529-594.

2. McCarty, G. A., J. R. Rice, M. L. Bember, and D. S. Pisetsky. 1982. Independent expression of autoantibodies in SLE. J. Rheumatol. 9:5-12.

3. Hayakawa, K., R. R. Hardy, D. R. Parkside, and L. A. Herzenberg. 1983. The Ly-1 B cells subpopulation in normal, immunodeficient and autoimmune mice. J. Exp. Med. 157:202-218.

4. Hayakawa, K., R. R. Hardy, M. Honda, L. A. Herzenberg, A. D. Steinberg, and L. Herzenberg. 1984. Ly1 B cells: functionally distinct lymphocytes that secrete IgM autoantibodies. Proc. Natl. Acad. Sci. USA. 81:2494-2498.

5. Monestier, M., A. Manheimer-Lory, B. Bellon, F. Alt, and C. Bona. 1986. Shared idiotypes and restricted Ig variable region heavy chain genes characterize murine autoantibodies of various specificities. J. Clin. Invest. 78:753-759.

6. Dighiero, G., P. Lymperi, D. Holmberg, I. Lundquist, A. Coutinho, and S. Avrameas. 1985. High frequency of natural autoantibodies in normal newborn mice. J. Immunol. 134:765-771.

7. Underwood, J. R., J. S. Pedersen, P. J. Chalmers, and B. H. Toh. 1985. Hybrids from normal, germ free, nude and neonatal mice produce monoclonal autoantibodies to eight different intracellular structures. Clin. Exp. Immunol. 60:417-426.

8. Prabhada, B. S., J. S. Junzo, T. Onodera, and A. L. Notkins. 1984. Lymphocytes capable of making monoclonal autoantibodies that react with multiple organs are a common feature of the normal B cell repertoire. J. Immunol. 133:2815-2817.

9. Stollar, B. D., and R. S. Schwartz. 1986. Monoclonal anti-DNA antibodies. The targets and origins of SLE autoantibodies. Ann. NY Acad. Sci. 465:192-199.

10. Guilbert B., G. Dighiero, and S. Avrameas. 1982. Naturally occurring antibodies against nine common antigens in human sera. $J$. Immunol. 128:2779-2787.

11. Eisenberg, R. A., S. Y. Craven, and P. L. Cohen. 1987. Isotype progression and clonality of anti-Sm autoantibodies in MRL/1pr mice. J. Immunol. 139:728-733.

12. Hahn, B. H., and F. M. Ebling. 1987. Idiotype restriction in murine lupus; high frequency of three public idiotypes on serum IgG in nephritic NZB/NZW F 1 mice. J. Immunol. 138:2110-2118.

13. Datta, D. K., H. Patel, and D. Berry. 1987. Induction of a cationic shift in IgG anti-DNA autoantibodies. J. Exp. Med. 165:1252-1268.

14. Schlomchik, M., D. Nemazee, J. Van Snick, and M. Weigert. 1987. Variable region sequences of murine IgM anti-IgG monoclonal autoantibodies (rheumatoid factors). J. Exp. Med. 165:970-987.

15. Schlomchik, M. J., A. Marshak-Rothstein, C. B. Wolfowicz, T. L. Rothstein and M. G. Weigert. 1987. The role of clonal selection and somatic mutation in autoimmunity. Nature (Lond.). 328:805811 .

16. Klinman, D. M., and A. D. Steinberg. 1987. Systemic autoimmune disease arises from polyclonal B cell activation. J. Exp. Med. 165:1755-1760.

17. Klinman, D. M., and A. D. Steinberg. 1986. Proliferation of anti-DNA-producing NZB B cells in a non-autoimmune environment. J. Immunol. 137:69-75.

18. Klinman, D. M., and A. D. Steinberg. 1987. Similar in vivo expansion of B cells from normal DBA/ 2 and autoimmune NZB mice in xid recipients. J. Immunol. 139:2284-2289.

19. Klinman, N. R., and G. Aschinazi. 1971. The stimulation of splenic foci in vitro. J. Immunol. 106:1338-1344.

20. Klinman, N. R. 1971. Purification and analysis of 'monofocal' antibodies. J. Immunol. 106:1345-1352.

21. Gearhart, P. J., N. H. Segal, and N. R. Klinman. 1975. Production of antibodies of identical idiotype but diverse immunoglobulin class by cells derived by a single stimulated cell. Proc. Natl. Acad. Sci. USA. 72:1701-1711.

22. Cancro, M. P., D. E. Wylie, W. Gerhard, and N. R. Klinman. 1979. Patterned acquisition of the antibody repertoire: diversity of the hemagglutinin-specific B-cell repertoire in neonatal BALB/c mice. Proc. Natl. Acad. Sci. USA. 76:6577-6581.

23. Cowdery, J. S., S. M. Jacobi, A. K. Pitts, and T. L. Tyler. 1987. Defective $B$ cell clonal regulation and autoantibody production in NZB mice. J. Immunol. 138:760-764.

24. Klinman, D. M., and A. D. Steinberg. 1987. Novel ELISA and ELISA spot assays used to quantitate $B$ cells and serum antibodies specific for $\mathrm{T}$ cell and bromelated mouse red blood cell autoantigens. $J$. Immunol. Methods. 102:157-163.

25. Gearhart, P. J., N. D. Johnson, R. Douglas, and L. Hood. 1983. IgG antibodies to phosphorylcholine exhibit more diversity than their IgM counterparts. Nature (Lond.). 291:29-34.

26. Feller, W. 1968. In Introduction of Probability Theory and Its Application. Vol. I. 3rd Ed. John Wiley and Sons, Inc., New York. 230-231.

27. Scheffe, H. 1959. In The Analysis of Variance. John Wiley and Sons, Inc., New York. 66-67.

28. Freitas, A. A., B. Guilbert, D. Holmberg, G. Wennerstron, A. Coutinho, and S. Avrameas. 1986. Analysis of autoantibody reactivities in hybridoma collections derived from normal adult BALB/c mice. Ann. Inst. Pasteur. (Immunol.) 137 D:33-46.

29. Monestier, M., B. Bonin, P. Migliorini, H. Dang, S. Datta, R. Kuppers, N. Rose, P. Maurer, N. Talal and C. Bona. 1987. Autoantibodies of various specificities encoded by genes from the $V_{h} J 558$ family bind to foreign antigens and share idiotopes of antibodies specific for self and foreign antigens. J. Exp. Med. 166:1109-1124.

30. Nisonoff, A. 1984. Specificities, affinities and reaction rates of antihapten antibodies. In Molecular Immunology, Sinauer Associates Inc., Sunderland, MA. 29-43.

31. Sigal, N. H., P. J. Gearhart, J. L. Press, and N. R. Klinman. 1976. Late acquisition of a germ-line antibody specificity. Nature (Lond.). 259:51-52. 